This is the final peer-reviewed version of the following article:

Faber, Pamela, Pilar León Araúz, Juan Antonio Prieto Velasco, and Arianne Reimerink. 2007. Linking Images and Words: the Description of Specialized Concepts. International Journal of Lexicography 20, no. 1: 39-65. <http://dx.doi.org/10.1093/ijl/ecl038>

You can find more articles authored by LexiCon Research Group members at <http://lexicon.ugr.es>.

\title{
Linking Images and Words: the Description of Specialized Concepts ${ }^{1}$
}

\author{
PAMELA FABER \\ PILAR LEÓN ARAÚZ \\ JUAN ANTONIO PRiETo VELASCO \\ ARIANNE REIMERINK² \\ University of Granada
}

\begin{abstract}
A crucial issue in terminology management is how specialized concepts should be represented so as to provide the user with an adequate understanding of their meaning as well as sufficient knowledge of their location within the general knowledge structure of a scientific or technical domain. Such a conceptual representation should contain information in various formats. In this regard, linguistic and graphical descriptions of specialized entities play a major role in knowledge representation, especially when both converge to highlight the multidimensional nature of concepts as well as the conceptual relations within a specialized domain. In this article, we explore the nature of the links between the linguistic and graphical description of specialized concepts. In a multimodal conceptual description, we believe that the structured information in terminographic definitions should mesh with the visual information in images for a better understanding of complex and dynamic concept systems.
\end{abstract}

\section{Introduction}

Traditionally, the difference between lexicography and terminography, apart from the fact that the former studies general language and the latter specialized fields of knowledge, has been their methodological approach. Generally speaking, most lexicographic products are structured alphabetically, whereas terminographic resources tend to have a more conceptual organization. Nevertheless, as Bowker (2003: 155) points out, both lexicographers and terminologists work in a way that often combines elements of semasiological (form-based) and onomasiological (concept-based) approaches. In the last ten years or so specialized language and general language studies have begun to show an approximation in perspective as lexicographers and lexical semanticists now tend to take a more concept-based approach towards dictionary structure, and terminographers have begun to pay more attention to conceptual description or to the definition of terminological units (Faber et al. 2001, Faber et al. 2005, Faber et al. 2006). 
One example of this approximation is Frame Semantics (Fillmore 1976, 1982, 1985, Fillmore et al. 2003, Atkins et al. 2003). According to Fillmore and Atkins (1998), a 'frame' can be defined as a network of concepts related in such a way that one concept evokes the entire system. Frame Semantics, like terminography, is based on conceptual organization. In lexicography, frame-based dictionaries have been recently proposed by Boas (2005) and Martin (2006).

Frame Semantics, as a theoretical framework, is also consistent with recent research in cognitive neuroscience. Barsalou (2003) argues that the human conceptual system is organized according to situated simulations which act as an interface between cognition and perception. This situated, dynamic conceptual system is neither fully modal nor fully amodal and at the highest level of organization, categories are created to streamline the action-environment interface. The notion of frame provides an excellent tool to represent the dynamic processes that take place in specialized fields of knowledge in a way that is similar to human conceptual representation.

Terminography focuses on the representation of specialized concepts, and more specifically, on the macro and micro-structural design of term entries. Since the ultimate purpose of any terminological resource is to facilitate and enhance knowledge acquisition, the information contained in term entries should be internally as well as externally coherent. Coherence signifies the harmonious flow of information, cooperation, and order among the components of a larger entity, which in this case would be the knowledge resource. In this regard, internal coherence refers to the information contained in the data fields of each entry, whereas external coherence refers to how entries are interrelated within the context of a unified whole.

The wider set of options available for linguistic resources in electronic format has generated a corresponding debate regarding how specialized concepts should be represented so as to provide the user with an adequate understanding of a particular concept as well as sufficient knowledge of its location within the general conceptual network of a scientific or technical domain. Depending on the nature of the concept, it is often useful for such a representation to include information in both linguistic and graphical formats. It is our assertion that linguistic and graphical descriptions of specialized entities play a major role in the understanding process when both types of description converge to highlight the multidimensional nature of concepts ${ }^{3}$ as well as the set of conceptual relations typical of a specific subdomain. In this sense, multidimensional refers to the various ways of describing concepts as well as a specialized domain, using both hierarchical and non-hierarchical relations.

\section{Describing concepts}

We are currently engaged in a research project on knowledge representation in the domain of Coastal Engineering 4 . One of the products contemplated is a multimedia terminological knowledge base for this specialized field. The elaboration of this terminological resource has caused us to explore in some depth the nature of the links between the linguistic and graphical description of concepts. However, in a multimodal 
conceptual description, not just any resource will do since the structured information in terminographic definitions should mesh with the visual information in images in order to provide a deeper understanding of complex and dynamic concept systems.

\subsection{The linguistic description of concepts: terminographic definition}

According to Béjoint (1997: 19-20) definitions have never been given due importance in terminology. In many terminological databases, definitions are simply inserted in a cutand-paste fashion from other dictionaries, term bases, or knowledge resources, without taking into consideration both their internal and external coherence. However, definitions are mini-knowledge representations or frames, and accordingly, the organization of information encoded in definitions should be structured in regard to its perceptual salience as well as its relationship to information configurations in the definitions of other related concepts within the same category (Faber et al. 2001, Faber 2002). Martin (1998) underlines the fact that frames as definition models offer more consistent, flexible, and complete representations. When the information in such representations is enhanced with images that highlight the different types of conceptual information within each definition, the entry is substantially enriched.

According to Grinev and Klepalchenko (1999), the description of specialized domains can in many cases be based on the events that generally take place in them, and can be represented accordingly. Within our coastal engineering knowledge base, concepts are organized according to their conceptual category. Although there are various ways of presenting the conceptualization of a specialized domain, depending on the objectives of the knowledge resource, we have configured the most generic categories in a prototypical domain event or action-environment interface (Barsalou 2003: 513, Faber et al. 2005), which provides a frame for the organization of more specific concepts.

\section{The Coastal Engineering Event}

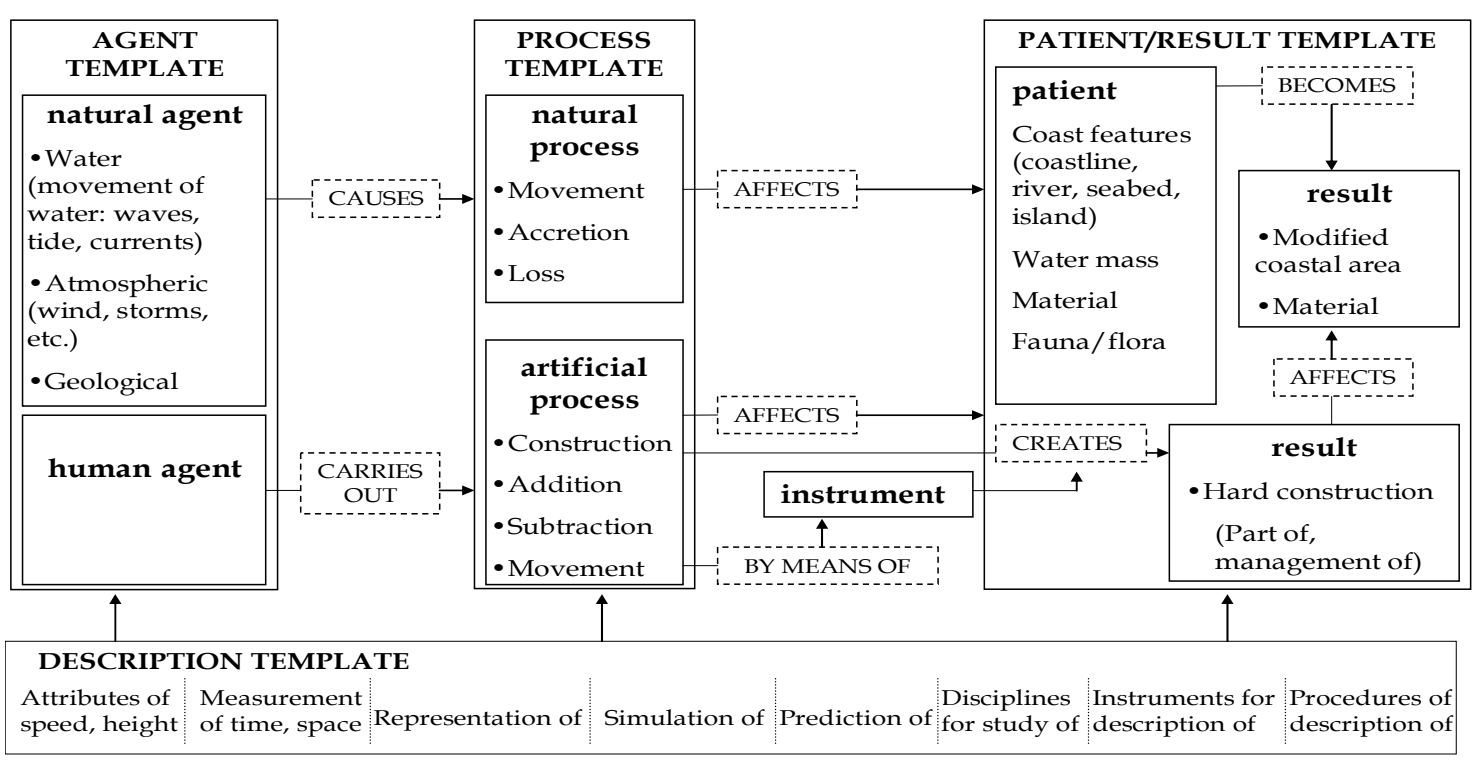

Figure 1. Coastal Engineering Event. 
As shown in Figure 1, our Coastal Engineering Event (CEE) is conceptualized as a dynamic process that is initiated by an agent (either natural or human), affects a specific kind of patient (a coastal entity), and produces a result. These macro-categories (AGENT $\rightarrow$ PROCESS $\rightarrow$ PATIENT/RESULT) are the concept roles characteristic of this specialized domain, and the CEE provides a model to represent their interrelationships. Additionally, there are peripheral categories which include INSTRUMENTS that are typically used during the CEE, as well as a category where the concepts of measurement, analysis, and description of the processes in the main event are included.

The more specific concepts within each category are organized in a hierarchical network where they are linked by both vertical (hierarchical) and horizontal (non-hierarchical) relations. In the database, these concepts can be accessed by clicking the hyperlink in the relevant macrocategory. In the following sections, we use concepts representing very diverse entities (i.e. groyne, beach nourishment and dredge) to show how linguistic and visual descriptions in each term entry reflect conceptual structure and relations.

2.1.1 Groyne and beach nourishment. In coastal engineering, a groyne is a wooden, concrete and/or rock barrier at right angles to the sea, which is often used to help prevent erosion along the coastline. As such, it is a maritime structure created by a natural or human agent. One of the activities that a human agent can carry out is CONSTRUCTION (artificial process). Construction results in a maritime structure, which is the category that groyne and other similar hard coastal defence structures belong to.

On the other hand, beach nourishment designates the process of replenishing an eroded beach with new material in order to serve the same purpose as groynes. Therefore, it is an artificial process implemented by a human agent. In our knowledge base, it thus belongs to the ADDITION category (artificial process), in the same way as all other soft coastal defence techniques.

Groyne as well as beach nourishment are members of the same mini-conceptual network, which is more meaningful when placed within the context of the prototypical coastal engineering event. In spite of belonging to two different macro-categories (PROCESS and RESULT), the link between soft and hard beach stabilization approaches is evident since they share the same basic function, and are both types of coastal defence solutions.

There are, of course, different ways of defining concepts, depending on the objectives of the dictionary project and the lexicographers involved. However, we have opted for a definitional format that: (1) makes category membership explicit; (2) reflects a concept's relations with other concepts within the same category; (3) specifies essential attributes and features. As shall be seen, the definitions of groyne and beach nourishment fulfil these conditions.

The definitions that we have formulated for coastal engineering terms are based on those found in other dictionaries and terminographic products that reflect the shared knowledge of specialized concepts. The analysis of such resources makes it possible to extract basic meaning components, identify the type of component, and elaborate 
definitions with external coherence on the basis of the same schema. For this type of analysis, three or more terminographic resources are used in order to obtain a consensus of the meaning components for each term. As shall be seen, the structure of definitions in each conceptual area has the same underlying template. Figure 2 is a segment of the definitional hierarchy in which groyne and beach nourishment are located.

\section{COASTAL DEFEnCE}

Hard coastal defence structure: impermeable coastal defence structure of concrete, wood, steel, and/or rock, which reflects a high proportion of incident wave energy.

Groyne: hard coastal defence structure, perpendicular to the shoreline, whose function is to protect a shore area, retard littoral drift, reduce longshore transport, and prevent beach erosion.

Breakwater: hard coastal defence structure, whose function is to protect a shore area, harbour, anchorage, or basin from waves and weather.

Detached Breakwater: breakwater without any coastal connection to the shore.

Soft coastal defence action: coastal defence action which aims to protect the coastline by enhancing natural processes and using natural forms of defence.

Beach nourishment: soft coastal defence action consisting of replenishing a beach with new dredged materials in order to protect the coastline from erosion, floods and storms.

Dune restoration: soft coastal defence action consisting of rebuilding an eroded dune through various processes like sand replenishment or revegetation.

Figure 2. Segment of the definitional hierarchy of coastal defence.

As shown in Figure 2, the genus or nuclear part the definitions is indicative of the IS_A relationship, and as a result, marks membership in a specific category as well as degree of specificity. In the case of groyne, the genus (i.e. hard coastal defence structure) shows: (1) its membership in the generic category of COASTAL DEFENCE; (2) its relationship to the immediately superordinate concept hard coastal defence structure; (3) its coordinate relationship with breakwater. As for beach nourishment, the genus (i.e. soft coastal defence action) highlights: (1) its membership in the generic category coastal defence; (2) its relationship to the immediately superordinate concept soft coastal defence action; (3) its coordinate relationship with dune restoration.

Furthermore, the differentiae or differentiating features specified in the definitions also provide valuable information because these are the characteristics that distinguish one concept from another within the same category. In this sense, Barsalou (1992) affirms that features implicitly show attributes and values that should become explicit in frames. In Terminology, they also establish parameters for the creation and organization of more specific terminological units that enable a multidimensional representation of concepts in the domain.

The analysis of the characteristics lexicalized in differentiae provides the defining features of groyne and beach nourishment, and also points to non-hierarchical relations that 
must be taken into account in any multidimensional representation of the concept. In fact, they constitute the parameters that categorize the various subtypes of groyne. These parameters can be observed in the template (Fig. 3) that underlies the definitions of all the terms designating coastal defence structures.

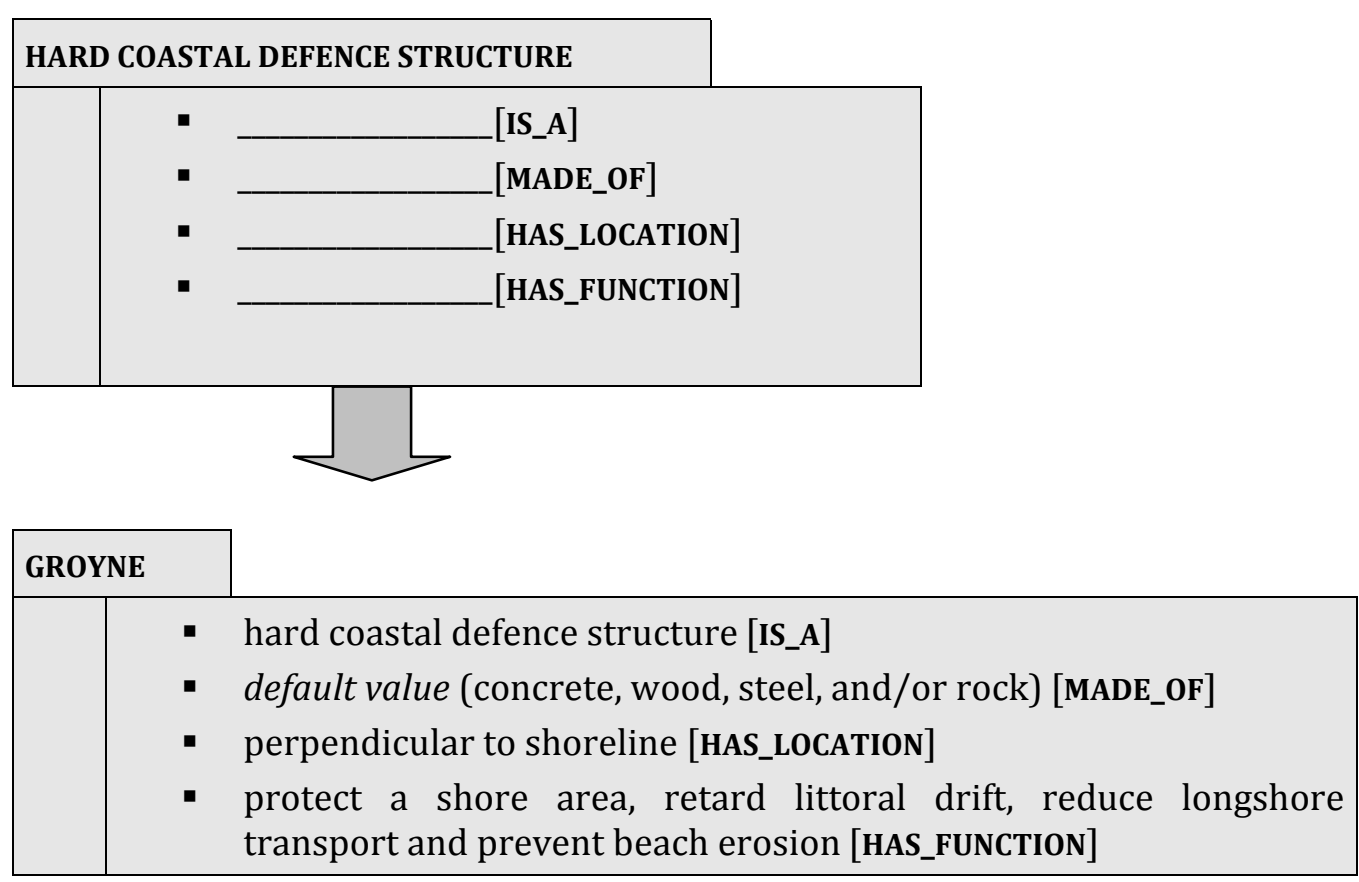

Figure 3. Activation of the definitional template for hard coastal defence structures in the definition of groyne.

As shown in Figure 3, the definitional template for hard coastal defence structure has four types of conceptual relations: (1) IS_A; (2) MADE_OF; (3) HAS_LOCATION; (4) HAS_FUNCTION.

In Fig. 4 the definitional template for soft coastal defence action also displays four types of conceptual relations: (1) IS_A; (2) RESULT_OF; (3) HAS_INSTRUMENT; (4) HAS_FUNCTION. Thus, a coastal defence template would activate the common relations IS_A and HAS_FUNCTION. In contrast, in the case of hard and soft solutions, conceptual relations vary in accordance with the nature of the concepts. Since hard coastal defence structures are objects and soft coastal defence actions are regarded as processes, their definitions show different types of information: the MADE_OF conceptual relation pertains to the description of a physical entity, whereas the RESULT_OF conceptual relation focuses on the final phase of the process involved.

Generally speaking, the linguistic description of groyne and beach nourishment as well as all of their coordinate and subordinate concepts within the conceptual area tend to follow these templates insofar as type, quantity, and configuration of information are concerned. In this way, definitions show a more uniform structure that complement the information encoded in the conceptual system, and directly refer to and evoke the underlying event structure of the domain. These templates can even be considered a conceptual grammar for the description of all types of coastal defence within the Coastal 
Engineering domain. This ensures a high degree of systematisation at the micro-structural level.
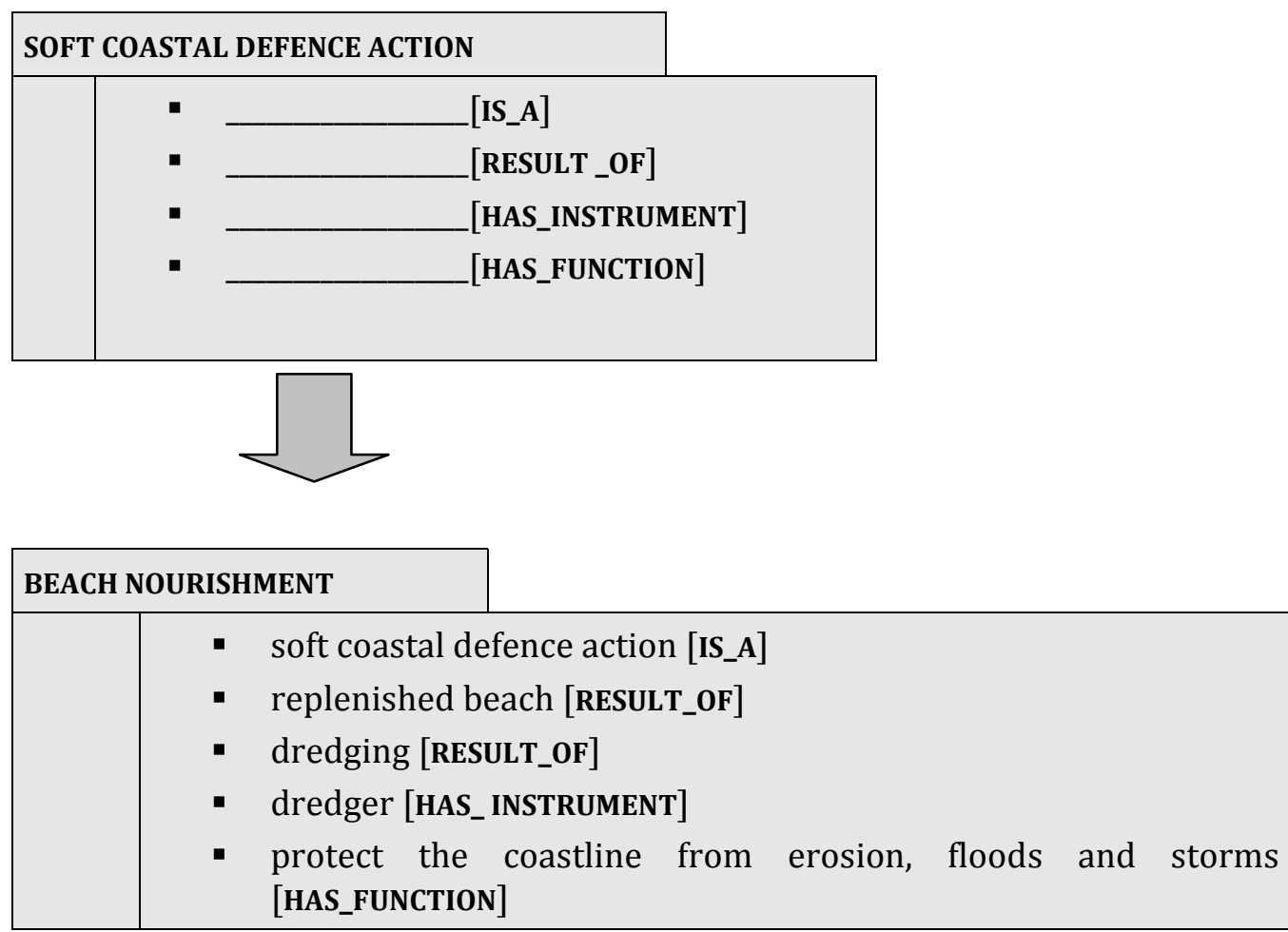

Figure 4. Activation of the definitional template for soft coastal defence actions in the definition of beach nourishment.

On a macro-structural level, the template is consistent with the dimensions specified for the designation of both concepts as shown in the network in Fig. 5.

Non-hierarchical relations are thus essential for dynamic knowledge representations because they enhance conceptual structure by enriching networks and encoding multiple relations between concepts (Faber 1999).

2.1.2. Dredge. Our approach can also be applied to processes like dredge, whose linguistic designation is a verb form. Though linguistically, both groyne and beach nourishment are noun phrases, conceptually speaking, groyne is an object and beach nourishment is a process. However, up to the present, verbs have received relatively little attention in specialized lexicography 5 though they designate a myriad of states and processes that are instrumental in the representation of specialized domains.

In the coastal engineering domain, dredge represents the action of removing sand in order to renourish a beach. As shown in previous examples, this activity is also carried out by a human agent. Consequently, dredge belongs to the SUBTRACTION category (artificial process). This shows how the CEE can be extremely useful in the categorization of this particular domain. The three examples in this paper belong to different subcategories which are, notwithstanding, interrelated at the macro-structural level (CEE, Fig. 1) as well 
as at the micro-structural level, where different categories often converge in the same subhierarchy (Fig. 5).

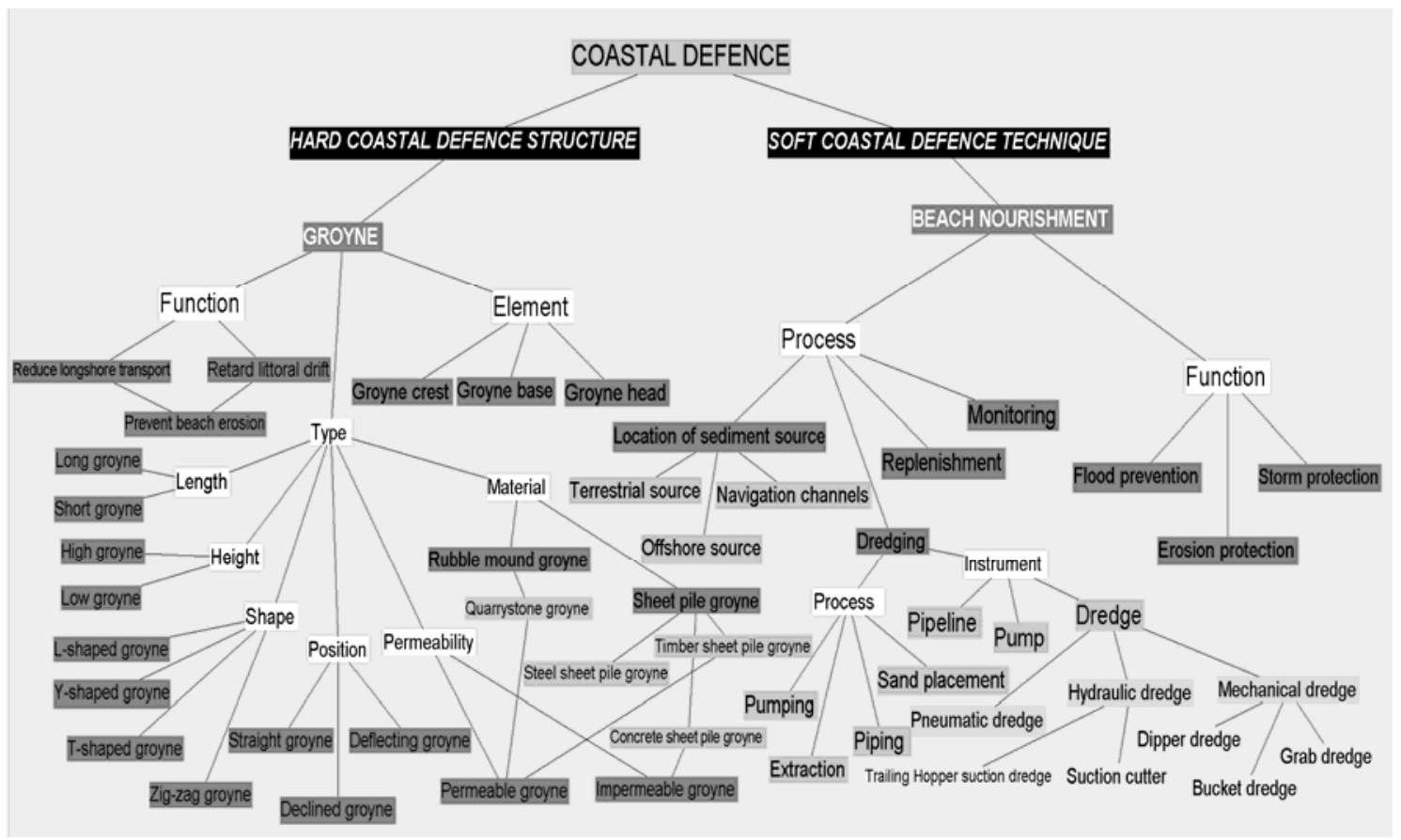

Figure 5. Conceptual network for groyne and beach nourishment.

Dredge is closely linked to beach nourishment since it obviously represents the action of dredging or the means of extracting sand to replenish an eroded beach. It consists of a sequence of subprocesses. This dynamism is not only reflected in the state of affairs of the verb, but also in its arguments, which belong to different categories within the event. (e.g. Beach can be a PATIENT as well as a RESULT). This is yet another argument in favour of a flexible, dynamic, and multidimensional process-oriented event as the underlying structure for this knowledge area.

The elements included in the definition of dredge are represented in the conceptual network in Fig. 5, and are basically the same as dredging. Since dredge is a process, its representation includes the action itself, the phases of the action, and the instruments used to carry it out. In this case, beach nourishment can be regarded as the function or purpose of dredge. The identification of category membership for verbs requires a different treatment. In concepts represented by verbs (i.e. actions or processes), the IS_A relationship, while still marking the degree of specificity, is specifically based on the participants in the event (argument structure) and the conceptual category to which the concept belongs.

The theoretical priniciples of the Functional Lexematic Model (FLM) (Martín Mingorance 1984, 1989, 1995; Faber and Mairal 1999) can be used for the conceptual organization of verbs. This model proposes a lexicon with two axes: a paradigmatic axis, which organizes lexemes hierarchically, and a syntagmatic axis, which describes the complementation patterns of each verb (Faber and Mairal 1999). Through the lexical decomposition of 
lexicographic definitions, verb concepts are placed in different domains and sub-domains within the paradigmatic axis. The verb lexicon is thus divided into twelve basic lexical domains, each of which can be said to have its own definitional template. The nuclear meaning of each verb is represented by a set of near-primitives, and lexical domains are divided into subdomains in accordance with semantic parameters or differentiae. The inventory of lexical domains is shown in Figure 6.

\begin{tabular}{|c|}
\hline Existence \\
\hline Change \\
\hline Possession \\
\hline Speech \\
\hline Emotion \\
\hline Action \\
\hline Manipulation \\
\hline Cognition/mental perception \\
\hline Movement \\
\hline General perception \\
\hline Sense perception \\
\hline Position \\
\hline
\end{tabular}

Figure 6. Lexical domains in the FLM.

Based on the above list, dredge belongs to the general category of movement in the same way as other similar action concepts in the coastal engineering domain, such as drain, pipe or excavate. However, not all of them necessarily have the same underlying structure. movement verbs are defined in terms of generic terms such as move, go or come. However, as semantic parameters are added to the paradigm through the designation of typical arguments, the hierarchy becomes more specific because the arguments (or participants in the process) are coastal engineering concepts. Thus, verb concepts sharing the same definitional template are those that have the same genus and the same argument structure as shown in Fig. 7.

\section{MOVEMENT}

\section{To cause somebody/something to move away from a place/thing/person}

remove [arg1, AGENT] to move away somebody/something [arg 2, PATIENT] from a place [arg 3, LOCATION]

dredge 1 [arg1, AGENT] to remove material [arg 2, PATIENT] from the bottom of any body of water. [arg 3, LOCATION] 
dredge 2 [arg1, AGENT] to remove beach material [arg 2, PATIENT] from underwater [arg 3, LOCATION] by pumping, extracting and piping it by means of a dredger for beach nourishment.

drain [arg1, AGENT] to remove liquid [arg 2, PATIENT] from any surface [arg 3, LOCATION]

Figure 7. Organization of verb concepts in the paradigmatic axis.

In this case, the genus of dredge (remove) marks its membership in MOVEMENT, and more specifically, in the subdomain of MOVEMENT_AWAY, whose members show a similar definitional template. For instance, a coherent and exhaustive terminographic description of drain would also include these same elements, whereas MOVEMENT verbs belonging to other subdomains would possibly show other patterns. Remove, the genus in the definitions of MOVEMENT_AWAY verbs, can imply that someone (arg 1) moves something (arg 2) away from somewhere (arg 3). These arguments (AGENT, PATIENT and LOCATION) function as default values within the same paradigm distinguishing coordinate concepts.

At the same time, depending on the specificity of its arguments, a concept can be regarded as more or less specialized, and thus be framed in a more restricted domain. The definition of dredge1, extracted from a general language dictionary, describes a very general event, whereas dredge 2 unequivocally refers to the coastal engineering domain, and more precisely to the beach nourishment process. The definitional template for verbs within this paradigm is shown in Fig. 8.
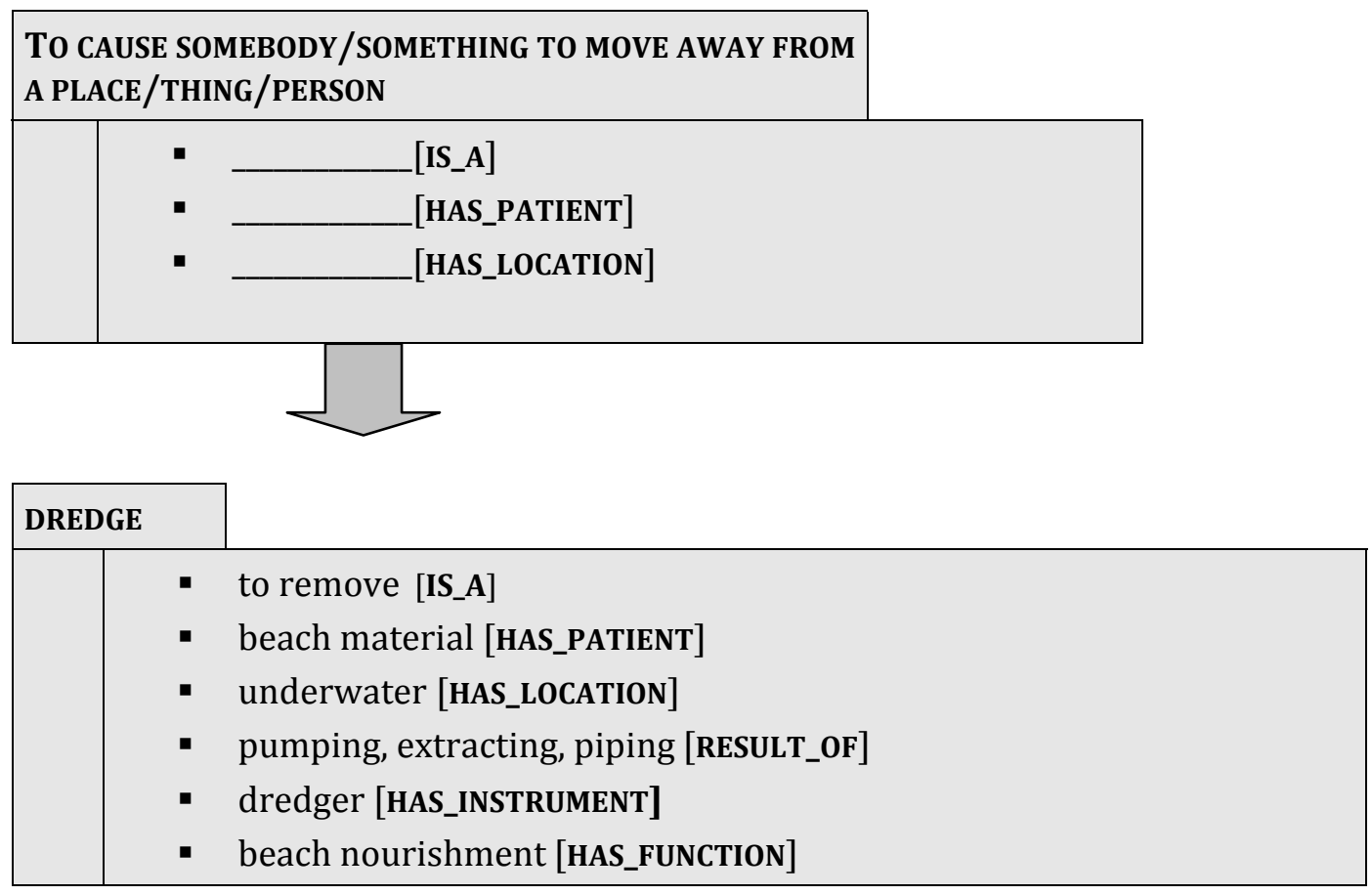

Figure 8. Activation of the definitional template of MOVEMENT_AWAY verbs in the definition of dredge.

In Fig. 8 the definitional template of MOVEMENT_AWAY concepts displays three types of conceptual relations: (1) IS_A; (2) HAS_PATIENT; (3) HAS_LOCATION. However, the specificity 
of dredge lies in the selection restrictions for the arguments, namely the fact that what is removed is an object not a person, and more specifically, beach material. Furthermore, the location is restricted to underwater. The representation of dredge also includes three more conceptual relations, which depict how this movement is carried out, the instrument used, and the reason why it is done.

In Fig. 8 the definitional template of MOVEMENT_AWAY concepts displays three types of conceptual relations: (1) IS_A; (2) HAS_PATIENT; (3) HAS_LOCATION. However, the specificity of dredge lies in the selection restrictions for the arguments, namely the fact that what is removed is an object not a person, and more specifically, beach material. Furthermore, the location is restricted to underwater. The representation of dredge also includes three more conceptual relations, which depict how this movement is carried out, the instrument used, and the reason why it is done.

\subsection{Typology of graphical information}

However definitions are not the only means of describing concepts. Images are also an important resource for this purpose. The inclusion of different types of visual representation is extremely helpful in specialized knowledge fields since images enhance textual comprehension and complement the linguistic information provided in other data fields.

Engineering dictionaries generally include occasional illustrations as a way of offering a more complete description of certain concepts (e.g. Flack and Möllerke 1999; Ching and Adams 2000; Smit and Chandler 2000; Adrien 2003). It is also worth noting that the Le grand dictionnaire terminologique (http://www.granddictionnaire.com), one of the most important terminological resources in Canada also contains illustrations as part of some of the term entries. In addition, almost all terminology management tools available on the market today provide the option for including graphics (e.g. MultiTerm, Termbase, etc.). Even though most terminologists and lexicographers do recognize the value of graphical information and make use of it whenever possible, illustrations are sometimes inserted in a relatively haphazard way in lexicographical and terminological resources without sufficient reflection on the visual representation of concepts. In our opinion, graphical material should be chosen in a principled way so as to be consistent with linguistic description.

Traditionally, images have been classified according to their morphology in categories of photographs, drawings, animations, videos, diagrams, charts, graphics, schemes, views, etc. (Darian 2001; Monterde 2002). However, it is more useful to categorize images in terms of their most salient functions (Anglin et al. 2004) or in terms of their relationship with the real-world entity that they represent. We have thus based our typology of images on the criteria of iconicity, abstraction and dynamism as ways of referring to and representing specific attributes of specialized concepts.

- Iconic images resemble the real-world object represented through the abstraction of conceptual attributes in the illustration. 
- Abstraction in an illustration is a matter of degree, and refers to the cognitive effort required for the recognition and representation of the concept thus represented (Levie and Lentz 1982; Park and Hopkins 1993; Rieber 1994).

- Dynamism implies the representation of movement (i.e. video and animation, as well as images showing different stages of a superordinate process respectively). However, such a representation need not include explicit movement if it illustrates the succession of discrete steps that make up the process.

\section{Linking conceptual descriptions and images}

\subsection{Groyne and beach nourishment}

As previously mentioned, the inclusion of images in term entries is based on the conceptual relations activated in the definition of the concept. In this respect, and in accordance with the definitional template for hard coastal defence structure and soft coastal defence action, the graphical resources in our image database highlight at least one of the following conceptual relations, IS_A, HAS_LOCATION, MADE_OF, HAS_INSTRUMENT_OF, RESULT_OF and HAS_FUNCTION, for the concept that they represent. They achieve this through iconicity, abstraction, and/or dynamism.

Iconicity is widely used in the representation of different types of coastal structures. The resemblance of the illustration to the real-world entity allows the user to identify the object or process in question by inferring its basic characteristics and linking them to previously stored knowledge structures. Iconicity is present in the linguistic description of the concept as well since the characteristics of the generic term are included in the genus of the subordinates. The use of a definitional template means that all of the definitions of category members will resemble each other to some degree.

Iconic images are especially prevalent when it is necessary to represent non-hierarchical relations, such as MADE_OF, which link the structure to the material that it is composed of (Fig. 9), and HAS_INSTRUMENT which shows the entity used to carry out an action (Fig. 10).

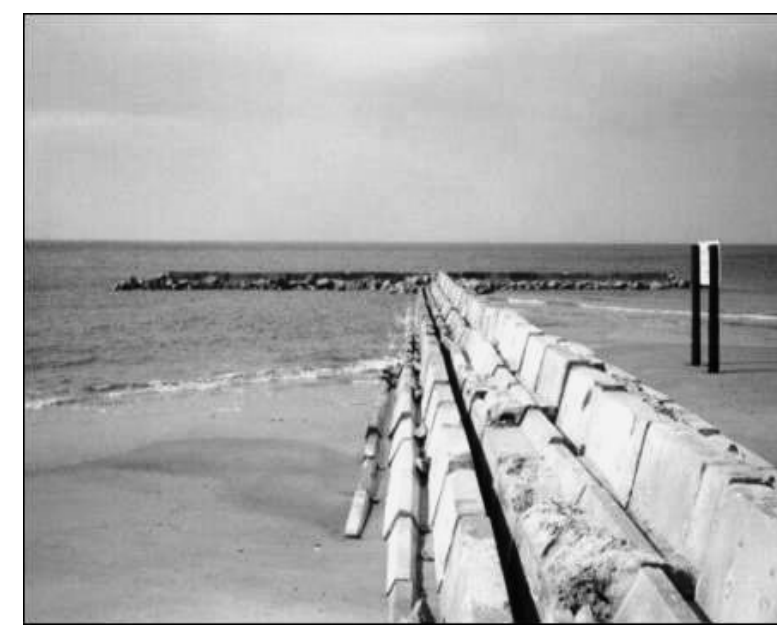

Figure 9. Concrete groyne: representation of the conceptual relation MADE_OF. 


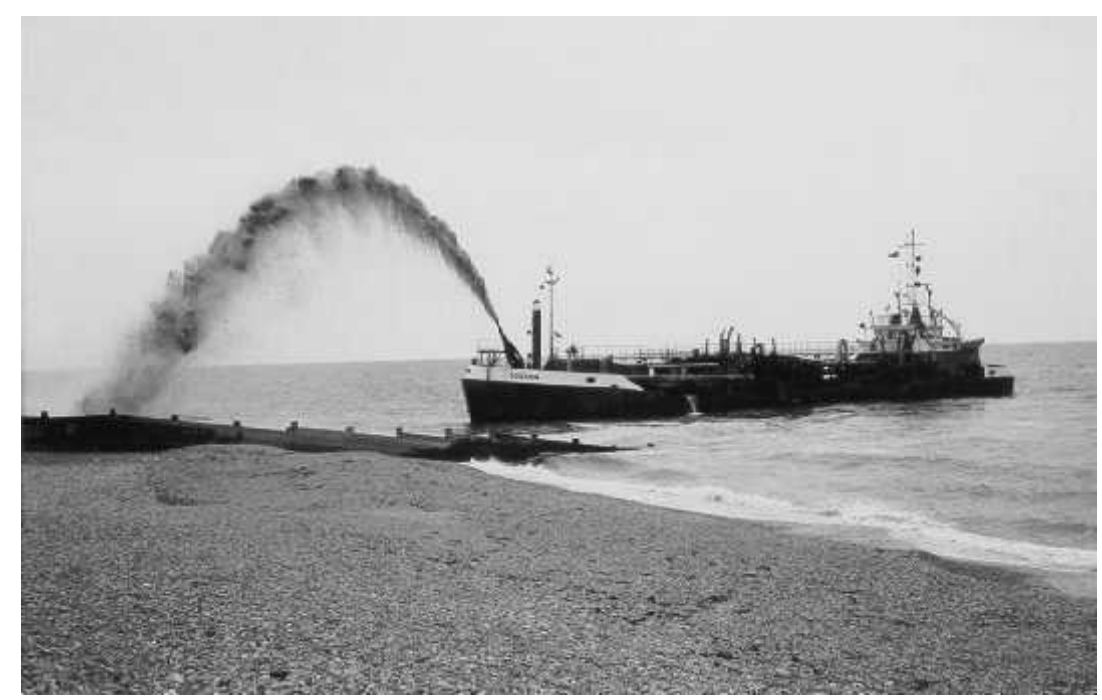

Figure 10. Beach nourishment: representation of the conceptual relation HAS_INSTRUMENT.

The level of abstraction can facilitate the understanding of conceptual relations such as HAS_LOCATION and IS_A. For example, in regards to groyne, location can be understood as the position of the coastal structure in reference to the shoreline (Fig. 11), or it can be understood as its position in reference to the sea bottom (Fig. 12). The abstraction of these images highlights this particular relation, while others such as groyne type, material, or function recede into the background and are not focused on.
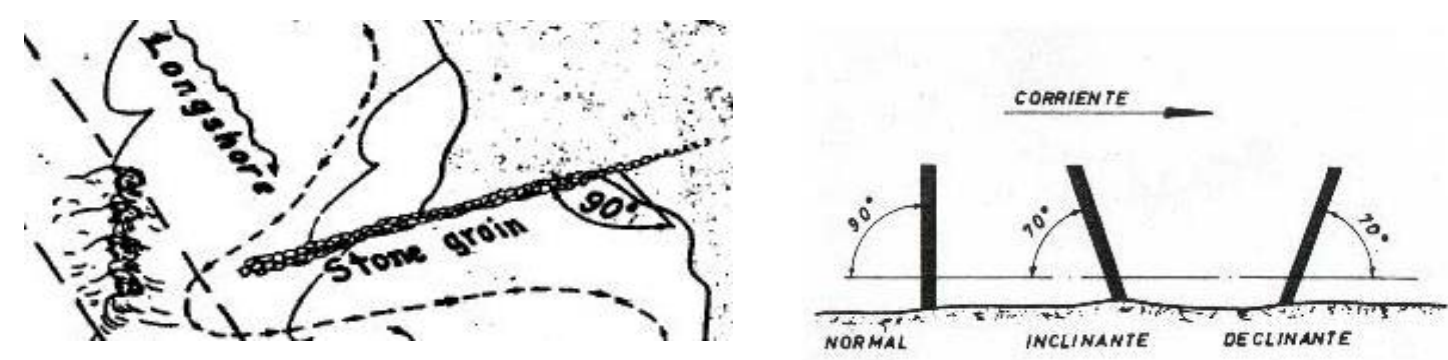

Figures 11 and 12. Representation of the conceptual relation HAS_LOCATION [POSITION] and HAS_LOCATION [SPATIAL CONFIGURATION].

On the other hand, since beach nourishment is a process, it can be understood as a sequence of phases. In this case the IS_A relation is encoded by images with a certain degree of abstraction. As shown in Fig. 13, the use of complementary short textual descriptions facilitates the understanding of its temporal and spatial location as well as all of the factors of the process. 


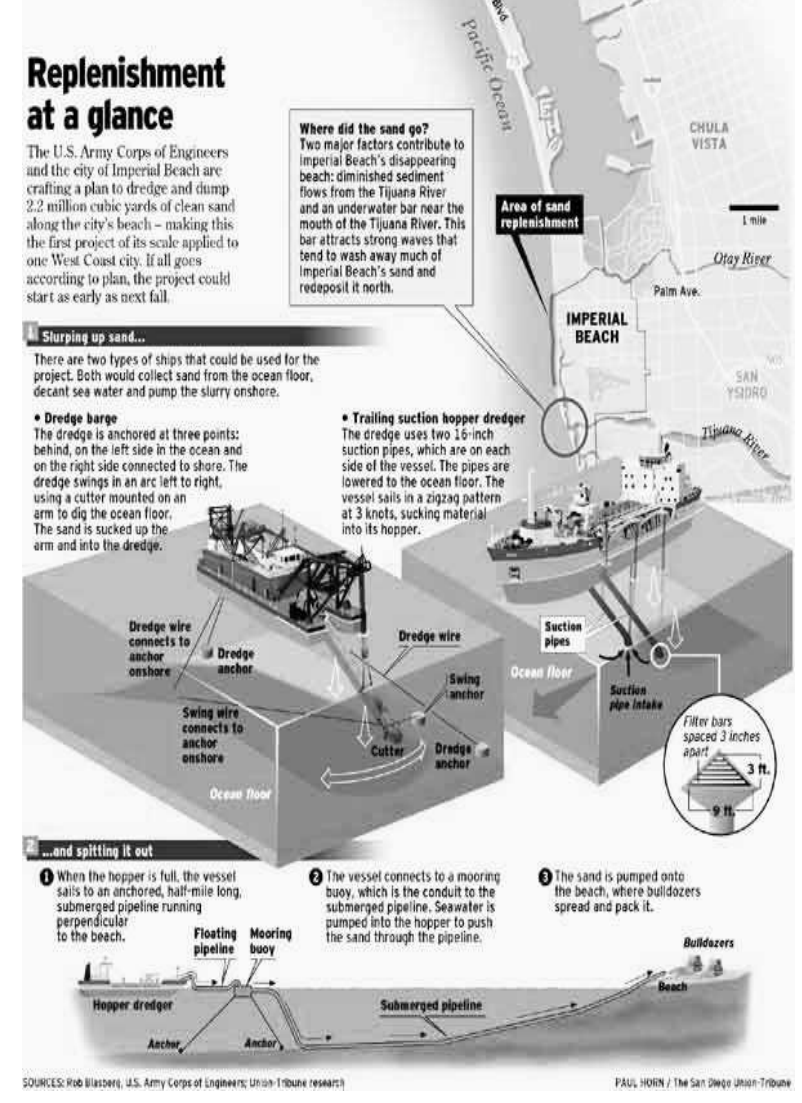

Figure 13. Dredge: representation of the conceptual relation IS_A.

Accordingly, since beach nourishment is an action carried out over a period of time, the relation RESULT_OF is best represented by abstract images that make explicit reference to the temporal nature of the process (Fig.14).

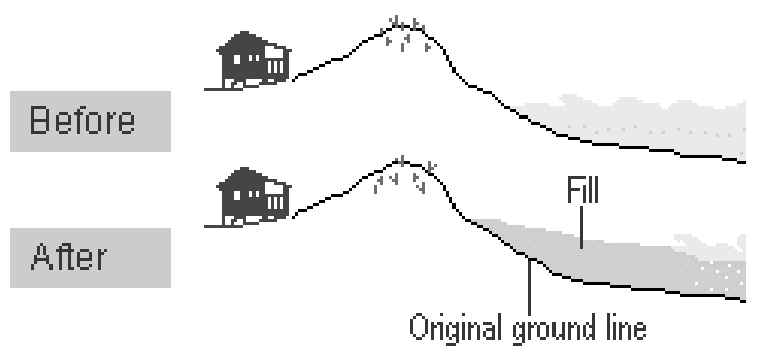

Figure 14. Beach nourishment: representation of the conceptual relation HAS_RESULT. 
Finally, the relation HAS_FUNCTION is generally represented by dynamic images. Function is one of the most important features for the description of both hard and soft coastal defence solutions since such structures are often constructed or implemented to cause a certain (positive) effect, but all too often bring about negative changes in the coastal environment that had not been foreseen. Since the illustration of a function means representing a process, dynamism is usually present, though evidently, this does not preclude the presence of degrees of iconicity or abstraction. Figs. 15a and 15b are two dynamic illustrations that represent the positive and negative effects of groynes on a shoreline.
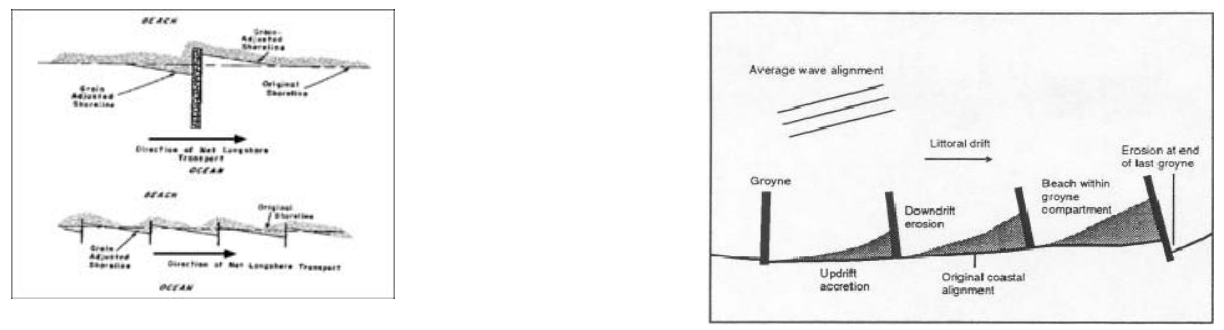

Figures 15a and 15b. Groyne-adjusted shoreline: representation of the conceptual relation HAS_FUNCTION.

Sometimes one illustration may not be enough to represent complex conceptual relations such as HAS_FUnCTION. The combination of two dynamic images (Figs. 16a and 16b) implements the protective function stated in the definition. Fig. 16a shows the different coastal processes responsible for sand gains and losses, whereas Fig. 16b represents the sand balance, whose restoration is the primary objective of beach nourishment.
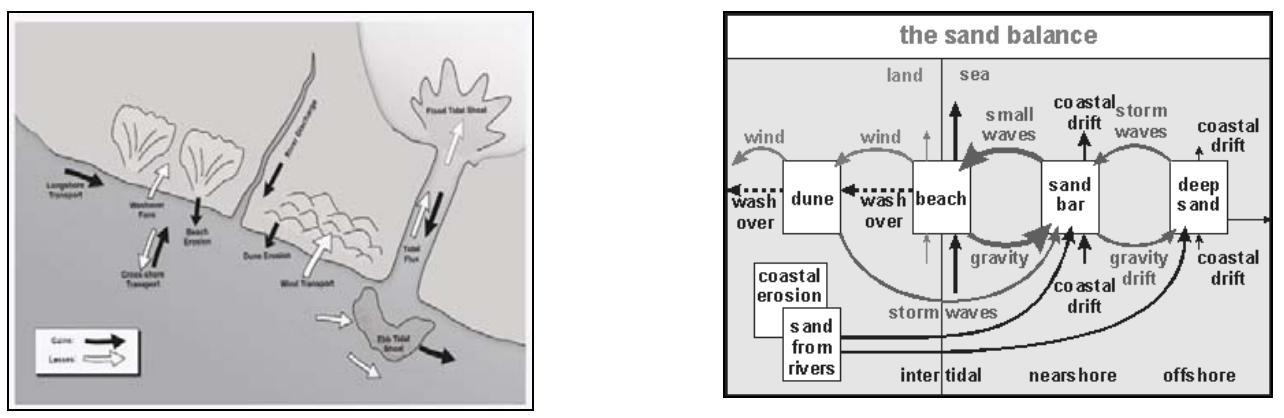

Figures 16a and 16b. Combination of two dynamic images: representation of the conceptual relation HAS_FUNCTION.

In these figures, dynamism is conferred by the use of symbols, such as arrows (representing movement), and textual information that link the pictures to the real world. Nevertheless, since they are non-iconic elements, a certain level of abstraction is also involved in arriving at the understanding that groynes retard longshore transport and littoral drift at the same time as beach nourishment provides a deposition of dredged sediments. As a consequence, they jointly contribute to an accretion of sediments in order to prevent beach erosion. 
Consequently, the entries for groyne and beach nourishment are accompanied by a set of images whose iconicity, abstraction, and/or dynamism are consistent with the information in their definition or linguistic description. The visual focus of each image is centred on a specific conceptual relation that is lexicalized in the terminographic definition. The linking of linguistic and graphical information in accordance with a definitional template typical of the conceptual area affords a more complete description and a better comprehension of specialized concepts (Figs. 17 and 18).

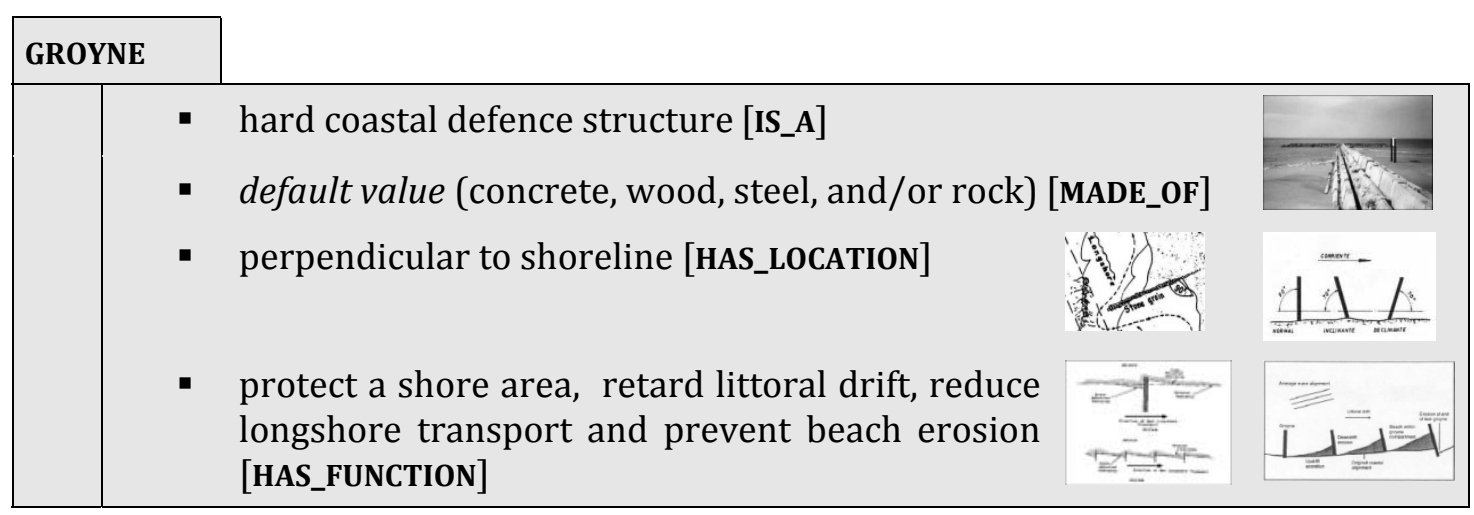

Figure 17. The convergence of linguistic and graphical descriptions of groyne.

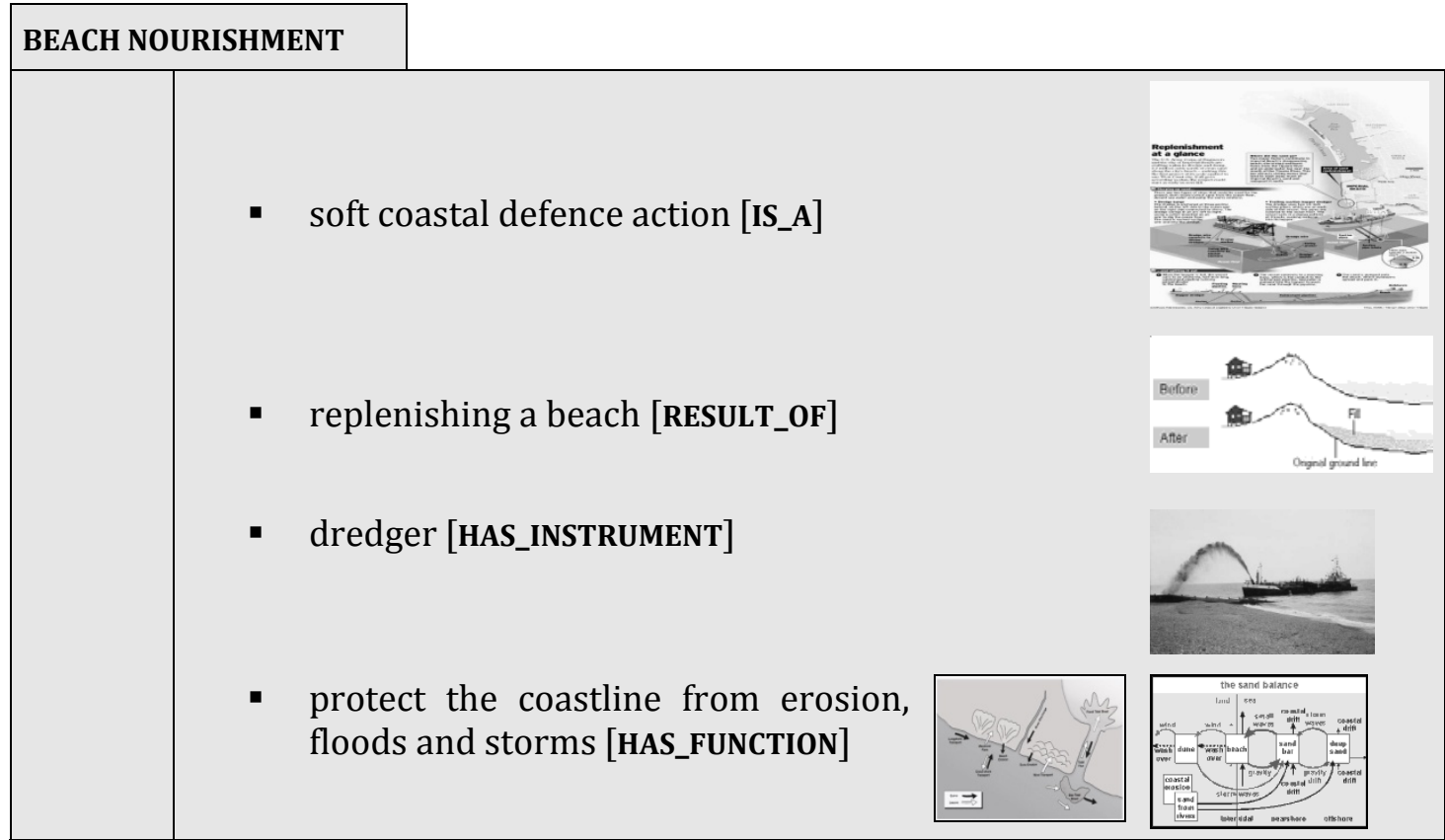

Figure 18. The convergence of linguistic and graphical descriptions of beach nourishment.

\subsection{Dredge}

Given the fact that dredge is a process, the IS_A relation is best conveyed by means of a dynamic image such as Fig. 19 which depicts the sequence of sand removal, pumping, piping and deposition. The combination of explicative text boxes and non-iconic elements, such as arrows, reduces the level of abstraction and facilitates the understanding of this concept. 


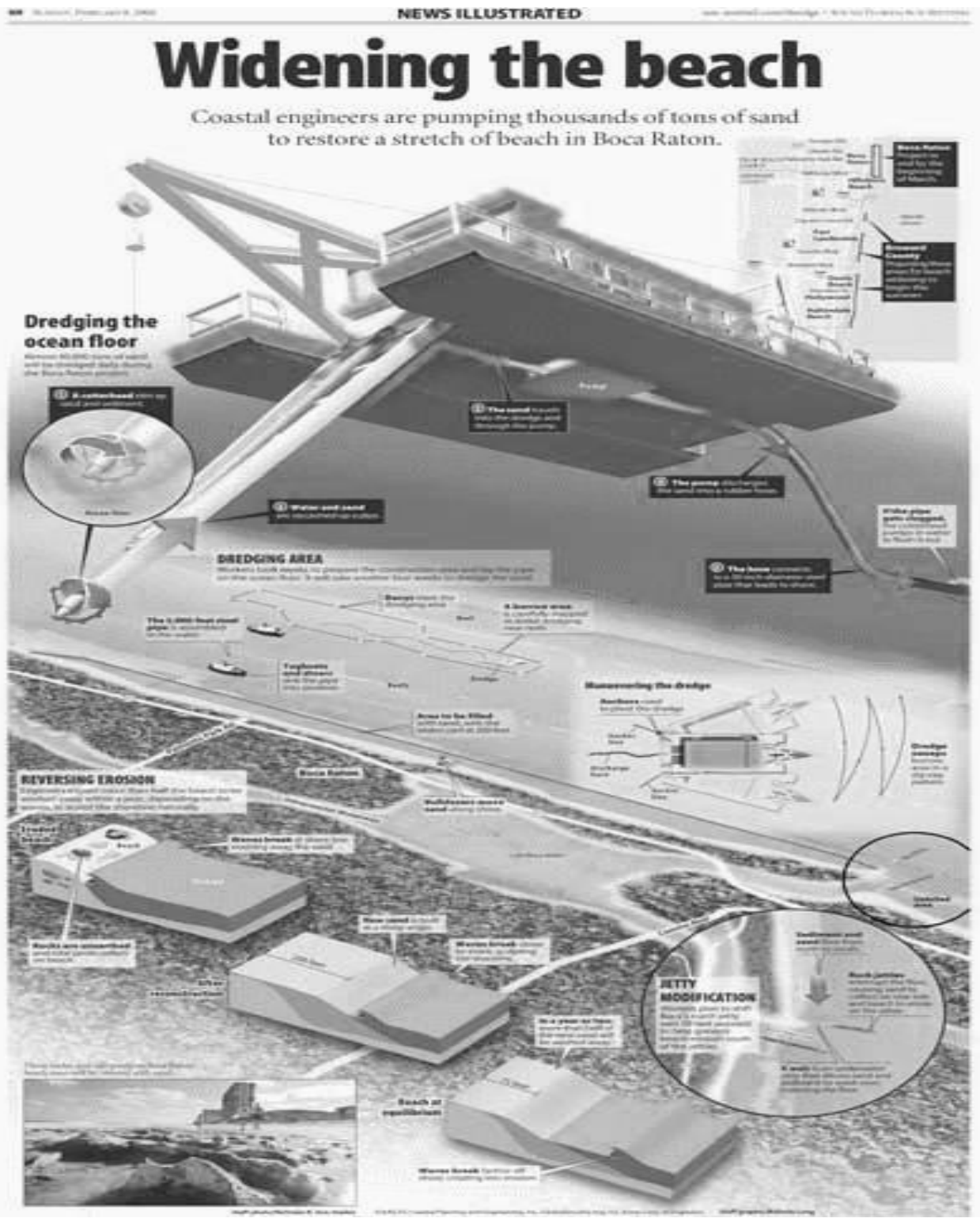

Figure 19. Dredging process: representation of the conceptual relation IS_A.

Dynamic images, which are somewhat less abstract, are also suitable for the representation of the RESULT_OF relation, which is the final phase of the dredge process. The combination of illustrations in Fig. 20 provides the user with an overall view of the stages in this process: pumping, extracting and piping. These process phases can be represented from a dual perspective, an aerial view and also a horizontal cross-section, which shows how the sand goes from the sea bottom onto the beach. 


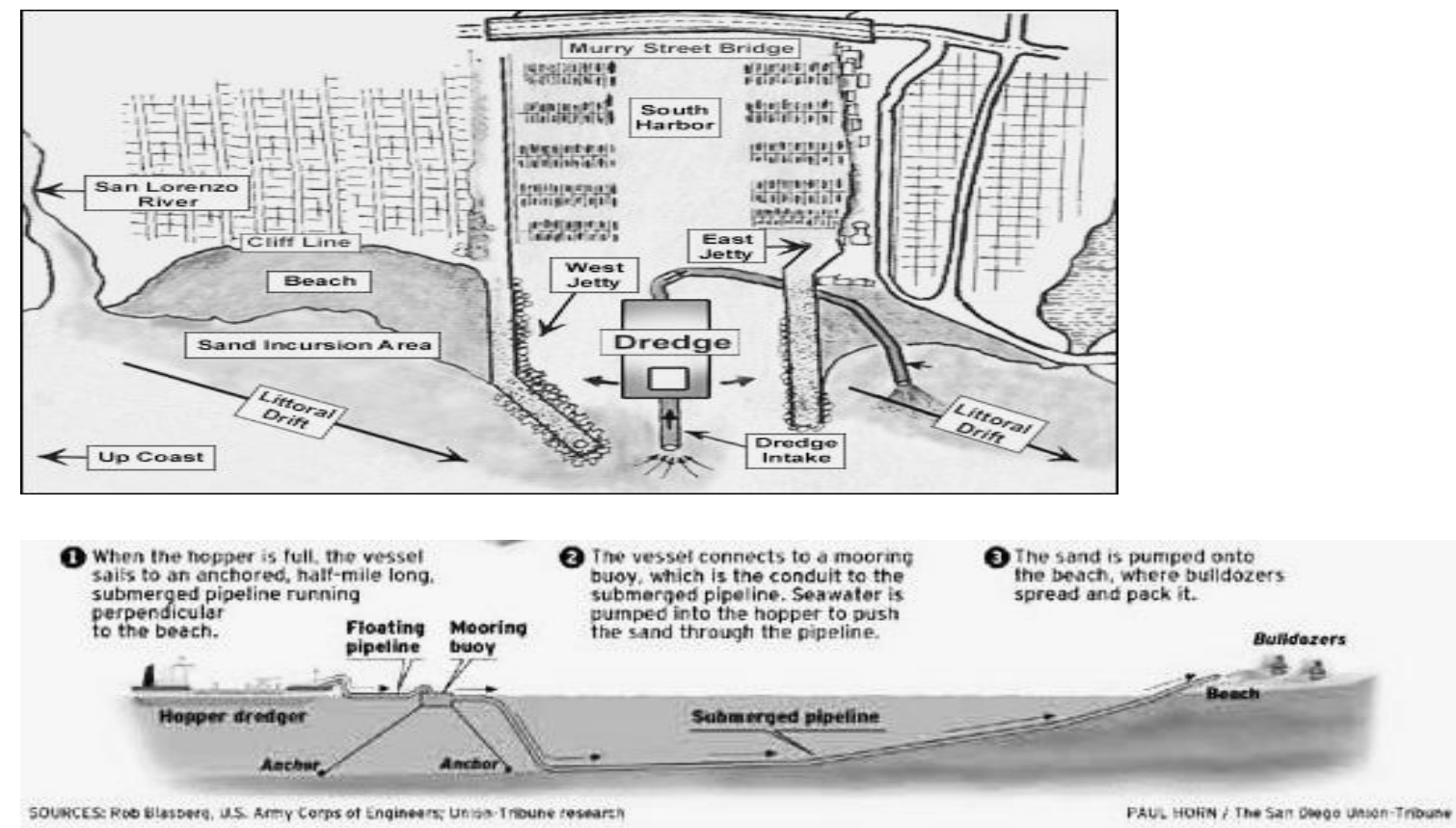

Figure 20. Dynamic illustrations: representation of the conceptual relation RESULT_OF.

Another important conceptual relation for dredge is HAS_LOCATION, which represents where the dredging equipment is situated. Since this relation is very easy to grasp, Fig. 21 has a very low level of abstraction, and merely shows the underwater location where the dredging process starts. The caption as well as iconic elements (e.g. dark and light shades for the representation of the sea background and the sea bottom as real-world entities) are also present in the illustration itself and contribute to the representation of HAS_LOCATION.

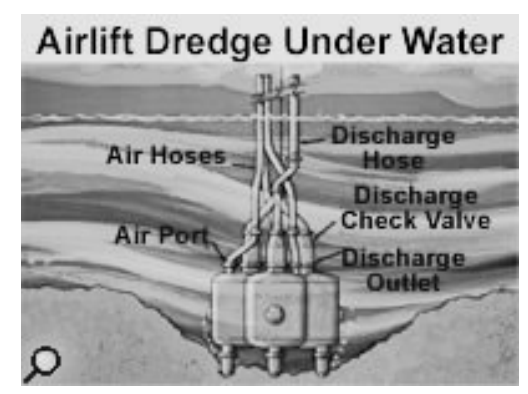

Figure 21. Underwater dredge: representation of the conceptual relation HAS_LOCATION.

The conceptual relation HAS_FUNCTION once again reflects the procedural nature of dredge. Consequently, dynamic illustrations depict the phases of the process. Fig. 22 shows the beach fill (or beach nourishment), which is the primary objective of a dredging project. 


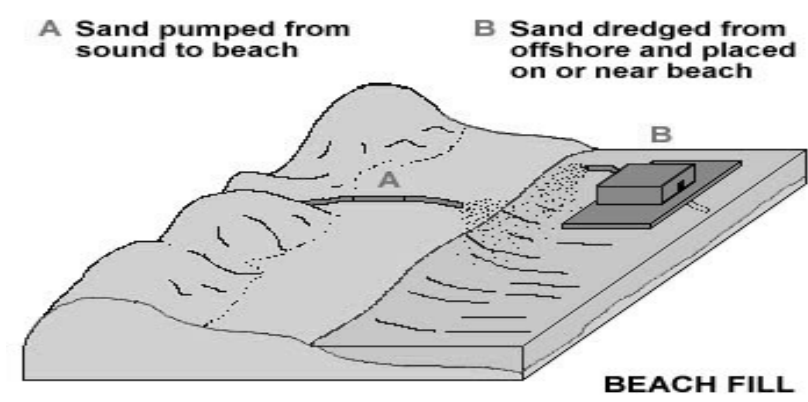

Figure 22. Beach fill: representation of the conceptual relation HAS_FUNCTION.

Iconicity is particularly significant when representing the conceptual relation HAS_INSTRUMENT since the different types of dredgers (hydraulic and mechanical) differ from one another in the position of the pumps and pipes. Iconic images reflecting the possible positions of the articulated piping equipment contribute to the representation of HAS_INSTRUMENT, because they greatly resemble the actual dredger vessel and the position of its dredging equipment (Figs 23, 24 and 25).

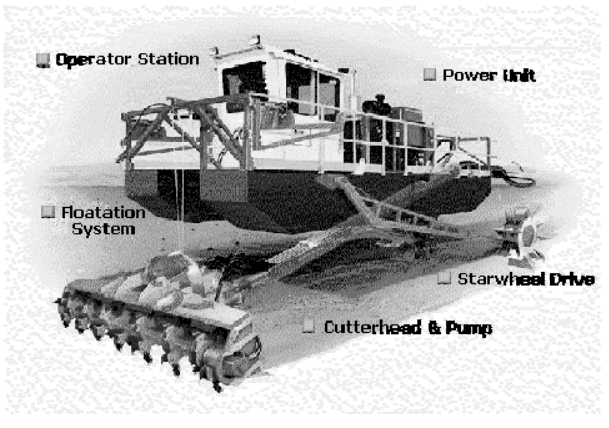

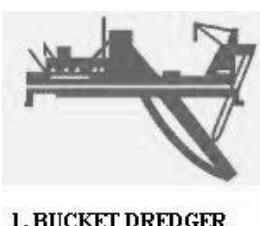

1. BUCKET DREDGER

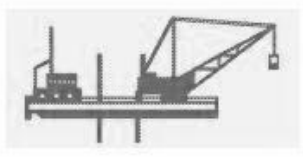

2. GRAB DREDGER

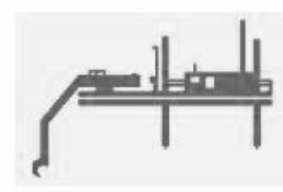

3. BACKHOE DREDGER

TYPES OF MECHANICAL DREDGERS

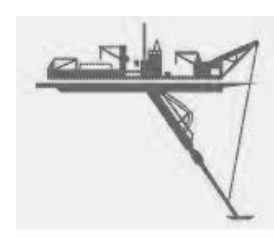

1. SUCTION DREDGER

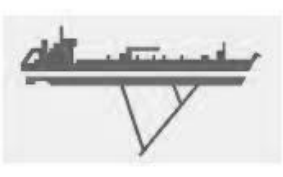

3. TRAILING SUCTION HOPPER DREDGER
TYPES OF HYDRAULIC DREDGERS

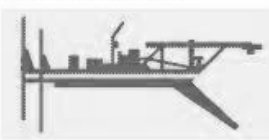

2. CUTTER SUCTION DREDGER

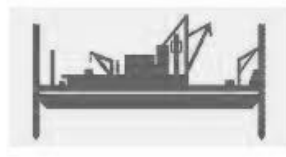

4. RECLAMATION DREDGER

Figures 23, 24 and 25. Different types of dredgers: representation of the conceptual relation INSTRUMENT_OF. 
In the same way, the conceptual relation HAS_PATIENT is iconically represented by a photograph of beach material as it is being dredged. Its resemblance to the real-world entity facilitates the identification of the material removed (sand or shingle) when dredging. The combination of both iconicity and dynamism highlights the role of beach material as the patient of dredge.

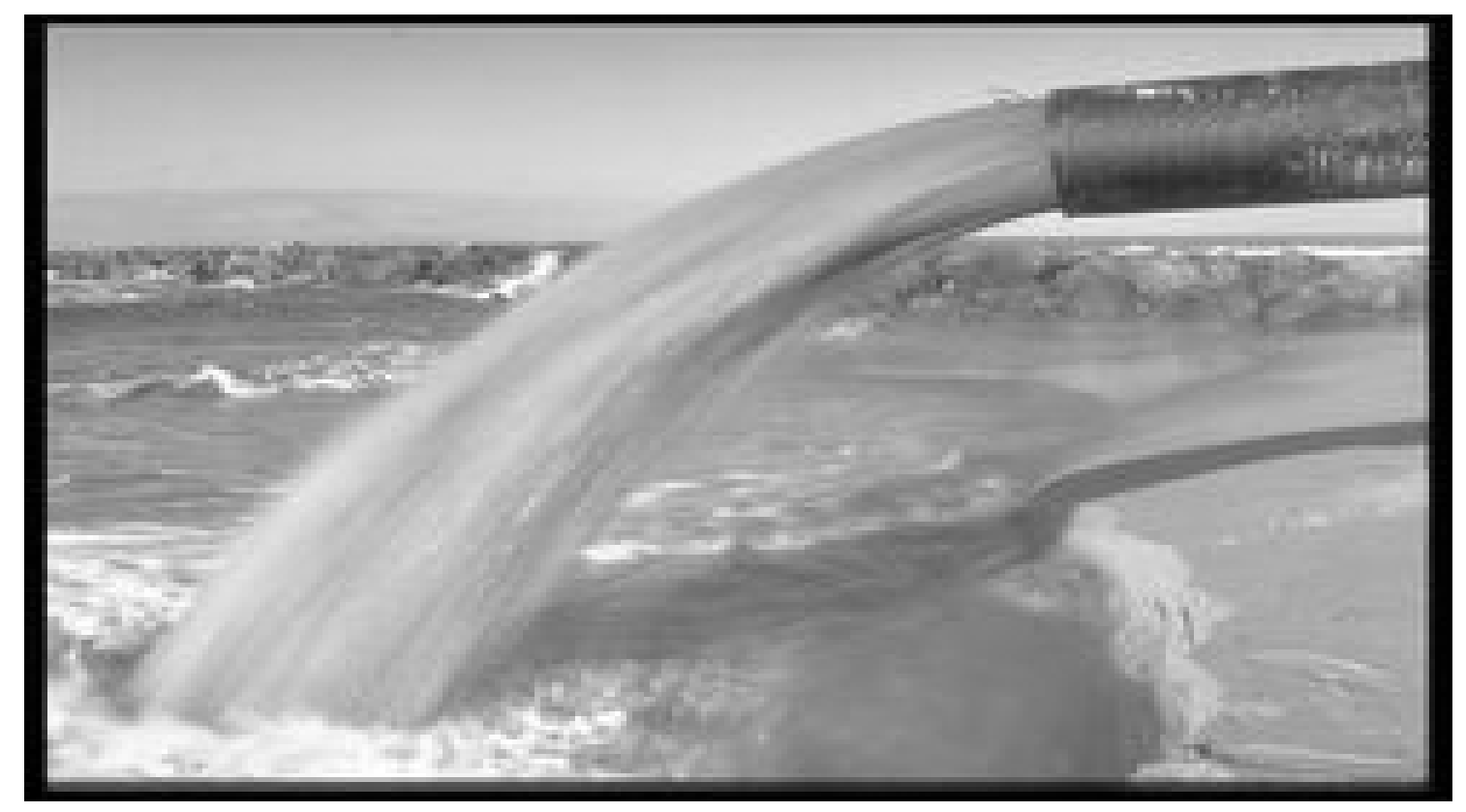

Figure 26. Beach material: representation of the conceptual relation HAS_PATIENT.

The three parameters used to classify illustrations in order to enable the representation of the conceptual relations behave rather differently when applied to procedural concepts designated by verbs. There is certainly more dynamicity in the images that represent such concepts, since most conceptual relations, IS_A, RESULT_OF and HAS_FUNCTION highlight the stages of the process in question. Similarly, these illustrations show a low level of abstraction which reduces complexity normally present in procedural concepts (Fig. 27).

\section{Conclusions}

In this article we have underlined the importance of interrelating different types of data in a terminological knowledge base in order to achieve a high degree of internal and external coherence. This is a complex issue since a database that aspires to be a knowledge resource cannot be a mere repository for bits and pieces of information that have been scavenged from different sources and gathered together in a kind of terminographic magpie's nest. Our assertion is that all elements in the data fields of term entries must be interrelated.

The entries for groyne, beach nourishment, and dredge reflect their location within the Coastal Engineering Event. The linguistic descriptions of these concepts are consistent with the definitions of others in the same area. The conceptual relations lexicalized in the category templates abstracted from definitional structure form a relational set that is characteristic of other related coastal structure entities. 


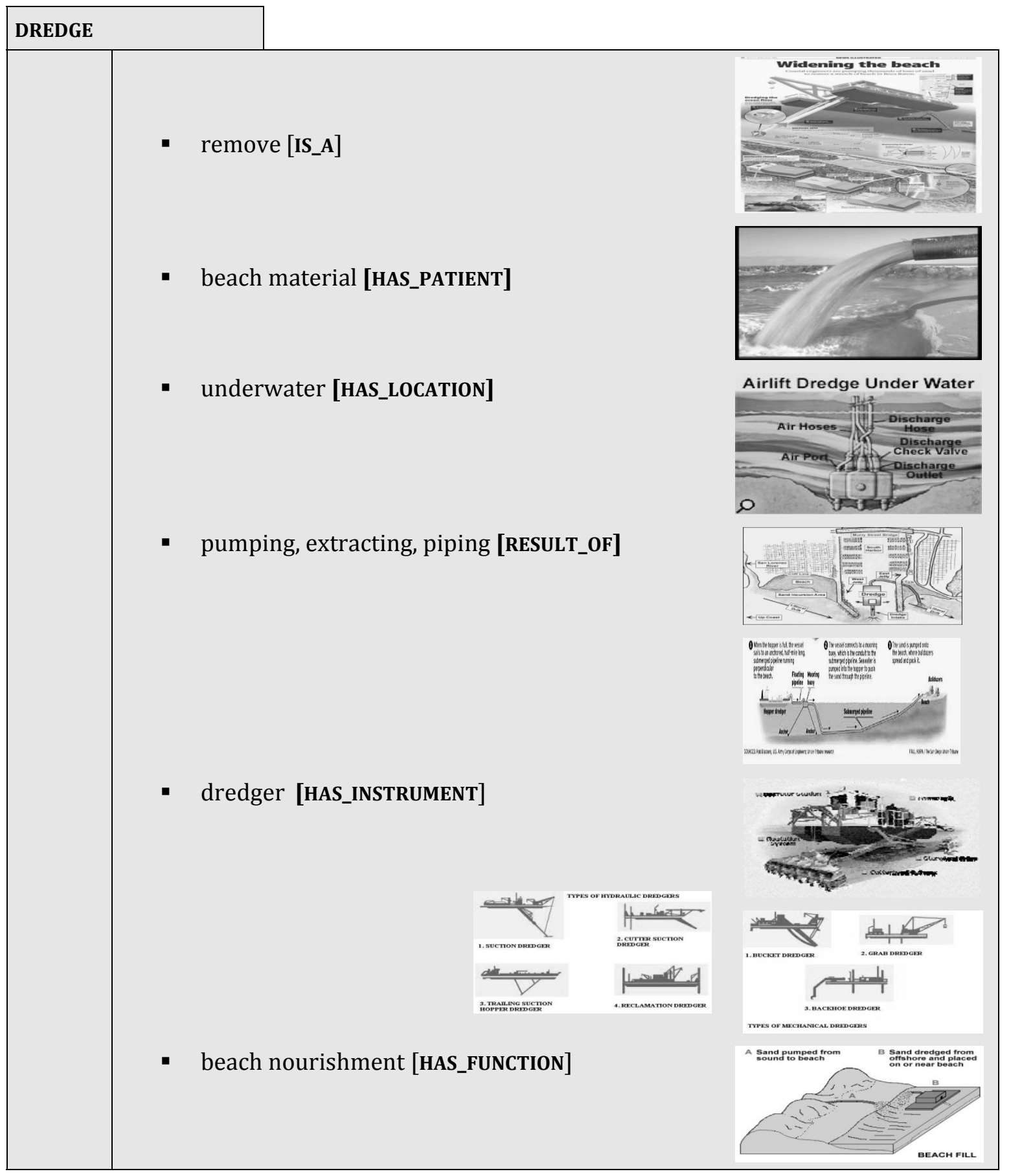

Figure 27. The convergence of linguistic and graphical descriptions of dredge.

In a parallel way, the graphical description of concepts should not be random. Such images can be chosen in a principled way so as to be in accordance with linguistic description. Illustrations should be selected so that they (1) focus on one or more aspects of the core template information as activated in the linguistic description of the concept; (2) possess the level of iconicity, abstraction, and/or dynamism that best portrays the attribute/s of the concept. 
In conclusion, linguistic and graphical descriptions of specialized entities play a major role in the understanding process when both types of description converge to highlight the multidimensional nature of concepts (Bowker 1997; Bowker and Meyer 1993) as well as the set of conceptual relations typical of a specific subdomain.

\section{Notes}

1. This article is a revised and expanded version of a paper presented at the 2006 Euralex Conference in Turin, Italy. The research is part of the project PuertoTerm: knowledge representation and the generation of terminological resources within the domain of Coastal Engineering, BFF2003-04720, funded by the Spanish Ministry of Education.

2. The authors would like to thank the two anonymous reviewers for their helpful suggestions.

3. Bowker and Meyer (1993) and Bowker (1997) advocate a multidimensional representation for concepts in specialized domains.

4. PuertoTerm is a research project whose principal objective is the generation of terminological resources for the representation of specialized concepts in the domain of Coastal Engineering.

5. An exception to the general tendency in lexicography and specialized lexicography to focus on nouns and ignore verbs is the work done by Fellbaum $(1990,1998)$ and L'Homme $(2002,2003,2006)$.

\section{References}

Adrien, Nicholas 2003. Computational Hydraulics and Hydrology: An Illustrated Dictionary. Boca Raton, FLA: CRC Press.

Anglin, G. Vaez, H. and Cunningham, K. 2004. 'Visual Representations and Learning: the Role of Static and Animated Graphics' in Jonassen, D. (ed.) Handbook of Research on Educational Communications and Technology. Hillsdale, NJ: Lawrence Erlbaum, 755794.

Atkins, Sue, Rundell, Michael, and Hiroaki, Sato 2003. 'The Contribution of Framenet to Practical Lexicography.' International Journal of Lexicography 16 (3): 334-357

Barsalou, Lawrence W. 1992. 'Frames, Concepts, and Conceptual Fields' in Lehrer, A. and Kittay, E. F. (eds.), Frames, Fields and Contrasts: New Essays in Semantic and Lexical Organization. Hillsdale, NJ: Lawrence Erlbaum, 21-71.

Barsalou, Lawrence W. 2003. 'Situated Simulation in the Human Conceptual System.' Language and Cognitive Processes 18, 513-562.

Béjoint, Henri 1997. 'Régards sur la définition en terminologie.' Cahiers de Lexicologie 70 (1): 19-26.

Boas, H. C. 2005. 'Semantic Frames as Interlingual Representations for Multilingual Lexical Databases.' International Journal of Lexicography 18 (4): 445-478.

Bowker, Lynne 1997. 'Multidimensional Classification of Concepts and Terms' in Wright, S.E. and G. Budin (eds.), Handbook of Terminology Management. Philadelphia/Amsterdam: John Benjamins, 131-143.

Bowker, Lynne 2003. 'Specialized Lexicography and Specialized Dictionaries' in Sterkenburg, P. van (ed.), A Practical Guide to Lexicography. Philadelphia/Amsterdam: John Benjamins, 154-164. 
Bowker, Lynne and Meyer, Ingrid 1993. 'Beyond 'Textbook' Concept Systems: Handling Multidimensionality in a New Generation of Term Banks' in K.D. Schmitz (ed.), TKE'93: Terminology and Knowledge Engineering, Frankfurt: Indeks Verlag, 123-137.

Ching, Francis D. K. and Adams, Cassandra 2000. Building Construction Illustrated. New York: Wiley.

Darian, Steven 2001. 'More than Meets the Eye: the Role of Visuals in Science Textbooks.' LSP \& Professional Communication 1 (1): 10-36.

Faber, Pamela 1999. 'Conceptual Analysis and Knowledge Acquisition in Scientific Translation.' Terminologie et Traduction 2: 97-123.

Faber, Pamela 2002. 'Terminographic Definition and Concept Representation' in Maia, Belinda, Haller, Johann, and Ulyrch, Margherita (eds.), Training the Language Services Provider for the New Millennium. Oporto: University of Oporto, 343-354.

Faber, Pamela and Mairal Usón, Ricardo 1999. Constructing a Lexicon of English Verbs. Berlin: Mouton de Gruyter.

Faber, Pamela, López Rodríguez, Clara, and Tercedor Sánchez, María Isabel 2001. 'Utilización de técnicas de corpus en la representación del conocimiento médico.' Terminology 7:2, 167-197.

Faber, Pamela, Márquez Linares, Carlos, and Vega Expósito, Miguel 2005. 'Framing Terminology: A Process-Oriented Approach'. META 50 (4): CD-ROM.

Faber, Pamela, Montero Martínez, Silvia, Castro Prieto, María Rosa, Senso Ruiz, José, Prieto Velasco, Juan Antonio, León Arauz, Pilar, Márquez Linares, Carlos, and Vega Expósito, Miguel (2006), 'Process-oriented Terminology Management in the Domain of Coastal Engineering.' Terminology 12:2, 189-213.

Fellbaum, Christiane. 1990. 'English Verbs as a Semantic Net'. International Journal of Lexicography 3 (4), 279-301.

Fellbaum, Christiane. (1998). 'Introduction' in C. Fellbaum (ed.) Wordnet: An Electronic Lexical Database. Cambridge, MA: MIT Press, 1-20.

Fillmore, Charles J. 1976. 'Frame Semantics and the Nature of Language' in Annals of the New York Academy of Sciences: Conference on the Origin and Development of Language and Speech 280, 20-32.

Fillmore, Charles J. 1982. 'Frame Semantics' in Linguistics in the Morning Calm, Seoul: Hanshin Publishing Co., 111-137.

Fillmore Charles J. 1985. 'Frames and the Semantics of Understanding.' Quaderni di Semantica 6: 222-253.

Fillmore, Charles and Atkins, Sue 1998. 'FrameNet and Lexicographic Relevance' in Proceedings of the ELRA Conference on Linguistic Resources, Granada, 417-423.

Fillmore, Charles J., Petruck, Miriam R.L., Ruppenhofer, Josef, and Wright, Abby 2003. 'Framenet in Action: the Case of Attaching.' International Journal of Lexicography 16 (3): 298-332.

Flack, H. K. and Möllerke, G. 1999. Illustrated Engineering Dictionary: Bildwörterbuch Maschinenbau und Elektrotechnik Englisch/Deutsch - Deutsch/Englisch (VDI-Buch). Berlin: Springer.

Grinev, S. and Klepalchenko, I. A. 1999. 'Terminological Approach to Knowledge Representation' in Sandrini, P. (ed.), '99. Terminology and Knowledge Engineering, Vienna: TermNet, 147-151. 
Levie, W. H. and Lentz, R. 1982. 'Effects of Text Illustrations: a Review of Research.' Educational Communication and Technology Journal 30: 195-232.

L'Homme, M. C. 2002. 'What can Verbs and Adjectives Tell us about Terms?' in Terminology and Knowledge Engineering, TKE 2002. Proceedings, August 28-30, 2002, Nancy, France, 65-70.

L'Homme, M. C. 2003. 'Capturing the Lexical Structure in Special Subject Fields with Verbs and Verbal Derivatives: A Model for Specialized Lexicography.' International Journal of Lexicography 16(4): 403-422.

L'Homme, M.C. 2006. 'Using Explanatory and Combinatorial Lexicology to Describe Terms' in Wanner, L. (ed.). Selected Lexical and Grammatical Topics in the MeaningText Theory. In Honour of Igor Mel'cuk, Amsterdam/Philadelphia: John Benjamins.

Martin, W. 1998. 'Frames as Definition Models for Terms' in Proceedings of the International Conference on Professional Communication and Knowledge Transfer. Vienna: Termnet, 2: 189-221.

Martin, W. (2006). 'Frame-based Lexicons and the Making of Dictionaries.' Proceedings of the 12th Euralex International Conference, Turin, Italy.

Martín Mingorance, L. 1984. 'Lexical Fields and Stepwise Lexical Decomposition in a Contrastive English-Spanish Verb Valency Dictionary' in Hartmann, R. (ed.). LEXeter 83: Proceedings of the International Conference on Lexicography. Tübingen, Germany: Max Niemeyer, 226-236

Martín Mingorance, L. 1989. 'Functional Grammar and Lexematics' in Tomaszcyk, J. and Lewandowska, B. (eds.). Meaning and Lexicography, Amsterdam/Philadelphia: John Benjamins, 227-253.

Martín Mingorance, L. 1995. 'Lexical Logic and Structural Semantics: Methodological Underpinnings in the Structuring of a Lexical Database for a Natural Language Processing' in Hoinkes, U. (ed.). Panorama der Lexikalischen Semantik, Tübingen, Germany: Gunter Narr, 461-474.

Monterde Rey, A. M. 2002. 'Terminología: estudio de las distintas formas de representación conceptual en textos técnicos y su relación con la traducción' in Actas de las II Jornadas de Jóvenes Traductores. Las Palmas de G. C.: Servicio de Publicaciones de la Universidad de Las Palmas de G. C., 147-156.

Park, O. and Hopkins, R. 1993. 'Instructional Conditions for Using Animated Visual Displays: A Review'. Instructional Science 22: 1-24.

Rieber, L.P. 1994. Computers, Graphics, and Learning. Madison, WI: Brown \& Benchmark.

Smit, Kornelis and Chandler, Howard 2000. Means Illustrated Construction Dictionary. (First edition 1991) Kingston, MA: R. S. Means Construction Publishers and Consultants. 